\title{
Status of polycrystalline relaxor-PT piezoelectric ceramics
}

\author{
PranatiPurohit*and Sushil Kumar Jain \\ Department of Applied Sciences \\ THE NORTHCAP University \\ Huda Sector 23A, Gurgaon, Haryana, India \\ *Email: pranatiprht@yahoo.co.in
}

\begin{abstract}
Perovskites like $\mathrm{Pb}$ (A B) $\mathrm{O}_{3}$, called relaxor materials, are electrostrictive in nature with cubicrhombohedra structure whereas $\mathrm{PbZrO}_{3}$ and $\mathrm{PbTiO}_{3}$ are ferroelectric having rhombohedra and tetragonal structures respectively. Relaxor materials show a strong dielectric relaxation behavior, why they are called relaxor. Its dielectric constant dependence on temperature shows a broad peak which shifts towards higher temperature at higher frequencies. Ferroelectric materials show a critical temperature, Curie temperature, at which the dielectric constant peaks. Compositions based on relaxor material with ferroelectric $\mathrm{PbTiO}_{3}$ form morphotropic phase boundary (MPB) at which rhombohedra to tetragonal phases coexist which makes the material easily polarizable with piezoelectric properties. It is similar to the MPB formed in piezoelectric ceramic materials, lead zirconatetitanate $\left(\mathrm{PbZrTiO}_{3}\right)$, but is inherently weaker as relaxor materials have partially orthorhombic with rhombohedra structure.
\end{abstract}

$\mathrm{Pb}\left(\mathrm{Mg}_{\mathrm{x}} \mathrm{Nb}_{1-\mathrm{x}}\right) \mathrm{O}_{3}-\mathrm{PbTiO}_{3}$

(PMN-PT)relaxorferroelectric ceramics have shown piezoelectric properties which are not as promising as $\mathrm{Pb}(\mathrm{ZrTi})$ $\mathrm{O}_{3}$. However, PMN-PT form single crystals which have shown ultra-high longitudinal piezoelectric strain coefficient $d_{33} \quad(>2000 \quad \mathrm{pC} / \mathrm{N})$ and electromechanical coupling factor $k_{33}(>0.9)$, much more than that shown by conventional piezoelectric ceramics. These merits have made these promising for a broad range of applications as ultrasonic transducers and piezoelectric actuators. $\mathrm{Pb}$ $\left(\begin{array}{llll}\left(\mathrm{Mg}_{1 / 3} \mathrm{Nb}_{2 / 3}\right) & \mathrm{O}_{3}-\mathrm{PbTiO}_{3} & \text { (PMN-PT) and } \mathrm{Pb}\end{array}\right.$ $\left(\mathrm{Zn}_{1 / 3} \mathrm{Nb}_{2 / 3}\right) \mathrm{O}_{3}-\mathrm{PbTiO}_{3}(\mathrm{PZN}-\mathrm{PT})$ However, relaxorPT binary systems have the drawbacks of low Curie temperature and low coercive fields. Second generation ternary systems like PMN-PZT-PT and PMN-PIN-PT have subsequently been investigated in recent years with much improved characteristics. Some of the single crystal relaxor-piezoelectrics based on binary and ternary systems have been commercialized. Piezoelectric ceramic ternary systems PMN-PIN-PT, PZN-PIN-PT have however higher Curie temperature and thus superior temperature stability, have higher coercive fields and hence low depolarization and superior ageing characteristics. Ceramic ternary systems have shown dielectric and piezoelectric properties comparable to PZTs. The effect of doping and changing the grain size on electro-mechanical and dielectric properties, which are known as intrinsic and extrinsic effects have not been sufficiently investigated in these systems. Both of these parameters affect the movement of ferroelectric domains and hence the dielectric and piezoelectric properties of these piezo-ceramics. Studies indicate that the optimum ratio of PMN and PT is different for relaxor-PT ceramics at $\mathrm{PMN}-36 \% \mathrm{PT}$ in comparison to the ratio $\mathrm{PMN}-33 \% \mathrm{PT}$ for single crystals as can be seen from the Table below $[1,2]$.

Table 1: Comparison of properties of PMN-36\%PT and $\mathrm{PMN}-33 \% \mathrm{PT}$

\begin{tabular}{|l|l|l|l|l|l|}
\hline & $\mathrm{E}_{33^{\mathrm{T}}}$ & $\begin{array}{c}\mathrm{d}_{33} \\
(\mathrm{pC} / \mathrm{N})\end{array}$ & $\mathrm{Q}_{\mathrm{m}}$ & $\mathrm{T}_{\mathrm{c}}{ }^{\circ} \mathrm{C}$ & $\begin{array}{c}\mathrm{E}_{\mathrm{c}} \\
(\mathrm{V} / \mathrm{mm})\end{array}$ \\
\hline $\begin{array}{l}\text { PMN- } \\
33 \% \mathrm{PT}\end{array}$ & 2920 & 453 & 124 & 160 & 180 \\
\hline $\begin{array}{l}\text { PMN- } \\
36 \% \mathrm{PT}\end{array}$ & 4830 & 499 & 17 & 580 & 710 \\
\hline
\end{tabular}

Likewise, other workers $[3,4]$ have shown the effect of grain size and doping on properties of PZT piezoceramics on the dielectric and piezoelectric properties. This paper presents a review study on the effect of grain size and doping on the dielectric and piezoelectric properties of ternary relaxor-PT ceramics. A study of likely effect on the properties of ternary relaxor-PT systems has been done with a view to suggest future perspective on improving the characteristics of these materials.

\section{References}

1.Shujun Zhangl, and Fei Li, 'High performance ferroelectric relaxor- $\mathrm{PbTiO}_{3}$ single crystals: Status and perspective', Journal of Applied Physics, 111,(2012) 031301-50

2. M. Pham-Thi, C. Augier, H. Dammak, P. Gaucher, Fine grains ceramics of PIN-PT, PIN-PMN-PT and PMNPTsystems: Drift of the dielectric constant under high electric field, Ultrasonics (2006)

3. Zhang Jialiang, ZhengPeng, Tan Yongqiang, Wang Chunlei, Grain-Size Effects on Dielectric and Piezoelectric Properties of Poled $\mathrm{BaTiO}_{3}$ Ceramics, http://www.paper.edu.cn

4. Clive A. Randall,Namchul Kim, John-Paul Kucera,Wenwu Cao, and Thomas R. Shrout, 'Intrinsic and Extrinsic Size Effects in Fine-Grained MorphotropicPhase-Boundary Lead ZirconateTitanate Ceramics', J. Am. Ceram. Soc., 81 [3] (1998) 677-88. 